International Journal of Medical Sciences

ISSN 1449-1907 www.medsci.org 2006 3(4):124-129

Short research communication

(C)2006 Ivyspring International Publisher. All rights reserved

\title{
Low temperature tolerance of human embryonic stem cells
}

\author{
Boon Chin Heng ${ }^{1}$, Kumar Jayaseelan Vinoth ${ }^{1}$, Hua Liu ${ }^{1}$, Manoor Prakash Hande ${ }^{2}$, Tong Cao ${ }^{1}$ \\ 1. Stem Cell Laboratory, Faculty of Dentistry, National University of Singapore, 5 Lower Kent Ridge Road, 119074 \\ Singapore. \\ 2. Department of Physiology, Yong Loo Lin School of Medicine, National University of Singapore, MD9, 2 Medical Drive, \\ 117597 Singapore.
}

Correspondence to: Dr. Tong Cao, e-mail: dencaot@nus.edu.sg Tel: +65-6516-4630 Fax: +65-6774-5701

Received: 2006.05.25; Accepted: 2006.07.21; Published: 2006.07.25

This study investigated the effects of exposing human embryonic stem cells (hESC) to $4^{\circ} \mathrm{C}$ and $25^{\circ} \mathrm{C}$ for extended durations of $24 \mathrm{~h}$ and $48 \mathrm{~h}$ respectively. Cell survivability after low temperature exposure was assessed through the MTT assay. The results showed that hESC survivability after exposure to $25^{\circ} \mathrm{C}$ and $4^{\circ} \mathrm{C}$ for $24 \mathrm{~h}$ was $77.3 \pm 4.8$ $\%$ and $64.4 \pm 4.4 \%$ respectively (significantly different, $\mathrm{P}<0.05$ ). The corresponding survival rates after $48 \mathrm{~h}$ exposure to $25^{\circ} \mathrm{C}$ and $4^{\circ} \mathrm{C}$ was $71.0 \pm 0.5 \%$ and $69.0 \pm 2.3 \%$ respectively (not significantly different, $\mathrm{P}>0.05$ ). Spontaneous differentiation of hESC after low temperature exposure was assessed by morphological observations under bright-field and phase-contrast microscopy, and by immunocytochemical staining for the pluripotency markers SSEA-3 and TRA-1-81. hESC colonies were assigned into 3 grades according to their degree of spontaneous differentiation: (1) Grade A which was completely or mostly undifferentiated, (2) Grade B which was partially differentiated, and (3) Grade C which was mostly differentiated. In all low temperature exposed groups, about $95 \%$ of colonies remain undifferentiated (Grade A), which was not significantly different $(\mathrm{P}>0.05)$ from the unexposed control group maintained at $37^{\circ} \mathrm{C}$. Additionally, normal karyotype was maintained in all low temperature-exposed groups, as assessed by fluorescence in situ hybridization (FISH) of metaphase spreads with telomere and centromere-specific PNA probes. Further analysis with m-FISH showed that chromosomal translocations were absent in all experimental groups. Hence, hESC possess relatively hightolerance to extended durations of low temperature exposure, which could have useful implications for the salvage of hESC culture during infrequent occurrences of incubator break-down and power failure.

Key words: human embryonic, stem cells, low temperature

\section{Introduction}

In vitro culture of human embryonic stem cells (hESC) often involves temporary exposure to reduced temperature outside the incubator during routine changing of culture media and serial passage. Additionally, there is also a possibility of hESC being exposed to low temperature for an extended duration of time, during infrequent occurrences of incubator break-down and power failure. Hence, it is imperative to characterize the low temperature tolerance of hESC with respect to their survivability, undifferentiated state and chromosomal normality. Physiologically, mammalian cells are naturally adapted to a constant body temperature. Hence, exposure to low temperature is likely to result in metabolic and physiological stress to hESC. Moreover, previous studies would imply that the mitotic spindle structure is unstable at low temperatures due to actin and tubulin depolymerization [1, 2]. This in turn can lead to chromosomal aberrations.

This study investigated the effects of exposing hESC to $4^{\circ} \mathrm{C}$ and $25^{\circ} \mathrm{C}$ for extended durations of $24 \mathrm{~h}$ and $48 \mathrm{~h}$ respectively. Cell survival after low temperature exposure was assessed through the MTT (Tetrazolium salt 3-(4, 5-dimethylthiazol-2-yl)-2,5diphenyltetrazolium bromide) assay [3]. Besides cell survivability, another critical parameter is whether the undifferentiated state of hESC is affected by exposure to low temperature. The degree of spontaneous differentiation of low temperature-exposed hESC colonies was assessed by morphological observations under bright-field and phase-contrast microscopy, as well as by immunocytochemical staining for the pluripotency markers SSEA-3 and TRA-1-81 [4]. Finally, chromosome analysis of the low temperature exposed hESC was done by fluorescence in situ hybridization (FISH) of metaphase spreads with telomere and centromere-specific peptide nucleic acid (PNA) probes, in the presence of DAPI (4'-6Diamidino-2-phenylindole) counterstaining [5].

\section{Materials and Methods}

\section{hESC, Media, Reagents \& Chemicals}

The hESC were obtained from the Wicell Research Institute Inc. (Madison, WI, USA), and were of the H1 line listed on the National Institute of Health (NIH) registry, which had received Federal approval for US government-supported research funding [6]. Unless otherwise stated, all liquid media, serum or serum replacement were purchased from Gibco BRL Inc. (Gaithersburg, MD, USA), while all other reagents 
and chemicals were purchased from Sigma-Aldrich Inc. (St. Louis, MO, USA).

\section{Culture and propagation of hESC in the undifferentiated state}

Undifferentiated hESC were maintained on a feeder layer of mitomycin C-inactivated murine embryonic fibroblast feeder (MEF) cells [7, 8]. These were harvested from CF1 inbred mouse strain purchased from Charles River Laboratories Inc. (Wilmington, MA, USA). The culture medium was DMEM/F12 supplemented with 20\% (vol/vol) Knockout (KO) serum replacement, $1 \mathrm{mM}$ L-glutamine, $1 \%$ nonessential amino acid, $100 \mathrm{mM} \quad \beta$ mercaptoethanol and $4 \mathrm{ng} / \mathrm{ml}$ bFGF. All cell cultures were carried out on 6-well culture dishes (Nunc Inc., Roskilde, Denmark) within a humidified 5\% $\mathrm{CO}_{2}$ incubator set at $37{ }^{\circ} \mathrm{C}$. The culture media was changed daily with routine passage of hES cells on a fresh MEF layer being carried out once a week. Dissociation of hES colonies into cell clumps for serial passage was achieved through treatment with $1 \mathrm{mg} / \mathrm{ml}$ collagenase type IV, for between 3 to $5 \mathrm{~min}$.

\section{Exposure of hESC to reduced temperature}

After 7 days of culture following the last serial passage, when the hESC colonies reached $70 \%$ to $80 \%$ confluence (1500 to 2000 cells $/ \mathrm{mm}^{2}$ ) on the culture dish (6-well plate), they were exposed to low temperature. There were altogether four experimental groups in this study: (1) exposure to $4^{\circ} \mathrm{C}$ for $24 \mathrm{~h},(2)$ exposure to $4^{\circ} \mathrm{C}$ for $48 \mathrm{~h}$, (3) exposure to $25^{\circ} \mathrm{C}$ for $24 \mathrm{~h}$, and (2) exposure to $25^{\circ} \mathrm{C}$ for $48 \mathrm{~h}$; together with a physiological control group maintained at $37^{\circ} \mathrm{C}$. Fresh culture media was changed prior to exposure to low temperature. However, no change of culture media took place during the entire period of exposure to low temperature. It must be noted that in real-life incubator break-down or emergency power failure, it is virtually impossible to maintain proper $\mathrm{pH}$, humidity and $\mathrm{CO}_{2}$ balance. For the $44^{\circ} \mathrm{C}$ and $25^{\circ} \mathrm{C}$ exposure groups, the 6-well culture plates were sealed at the sides with parafilm (for minimal evaporation), and placed in either a $4^{\circ} \mathrm{C}$ refrigerator, or back into the incubator reset at $25^{\circ} \mathrm{C}$. An atmosphere of $5 \% \mathrm{CO}_{2}$ was maintained only for the physiological control group $\left(37^{\circ} \mathrm{C}\right)$, while the low-temperature exposed groups were subjected to atmospheric levels of $\mathrm{CO}_{2}$.

\section{MTT assay to quantify hESC survival rate after exposure to low temperature}

The MTT assay [3] was performed to quantify the survival rate of hESC after exposure to low temperature $\left(4^{\circ} \mathrm{C}\right.$ and $\left.25^{\circ} \mathrm{C}\right)$ for extended durations (24h and 48h). It was assumed that hESC do not proliferate upon exposure to low temperature. This assumption is based on previous studies which demonstrated actin and tubulin depolymerization at low temperatures $[1,2]$, which would imply that the mitotic spindle is unable to form. Hence, for reference to the initial number of cells before exposure to low temperature, a 6-well culture dish with the same density of hESC colonies was subjected to the MTT assay on the same day that the other dishes were being exposed to low temperature. Briefly, this involved placing $0.5 \mathrm{ml}$ of $1 \mathrm{mg} / \mathrm{ml}$ MTT (SigmaAldrich Inc, St. Louis, MO, USA) constituted in PBS, to each well $\left(4.8 \mathrm{~cm}^{2}\right)$ of the 12-well dish, following by incubation for $4 \mathrm{~h}$ at $37{ }^{\circ} \mathrm{C}$ in the dark. After incubation, the MTT solution was removed and the cells were fixed with a few drops of formol-calcium $(0.4 \%(\mathrm{v} / \mathrm{v})$ formaldehyde with $1.0 \%(\mathrm{v} / \mathrm{v})$ anhydrous $\mathrm{CaCl}_{2}$ in deionised water), before a final rinse with PBS followed by air-drying. The MTT-formazan products were extracted in the dark at room temperature with $1 \mathrm{ml}$ of DMSO. One hundered microliters of the supernatant was later transferred into a 96-well flat-bottomed cell culture plates, which was measured spectrophotometrically at $570 \mathrm{~nm}$ using a Sunrise modular microplate reader (Tecan, Maennedorf, Switzerland). From the absorbance values, the survival rate after exposure to low temperature can then be computed by a simple formula, based on reference to the initial absorbance reading obtained for the unexposed control prior to exposing the rest of the culture dishes to low temperature (see Table 1).

Table 1 The majority of hESC survived after prolonged durations ( $24 \mathrm{~h}$ and $48 \mathrm{~h}$ ) of exposure to reduced temperature $\left(4^{\circ} \mathrm{C}\right.$ and $\left.25^{\circ} \mathrm{C}\right)$. The post-exposure survival rate was computed by dividing the MTT absorbance values obtained after exposure, with the initial absorbance reading for the unexposed physiological control maintained at $37^{\circ} \mathrm{C}$.

\begin{tabular}{|c|c|c|}
\hline & $\begin{array}{c}\text { Raw absorbance values obtained for } \\
\text { MTT assay (after correction for blank, } \\
\mathrm{n}=6)\end{array}$ & $\begin{array}{c}\% \text { survival } \\
\text { rate }\end{array}$ \\
\hline $\begin{array}{c}\text { Unexposed } \\
\text { Physiological } \\
\text { control } \\
\text { maintained at } \\
37 \mathrm{oC}\end{array}$ & $2.34 \pm 0.09$ & -- \\
\hline $4 \mathrm{oC}$ for $24 \mathrm{~h}$ & $1.51 \pm 0.10$ & $\begin{array}{c}64.4 \pm 4.4 \\
\%\end{array}$ \\
\hline $25 \mathrm{oC}$ for $24 \mathrm{~h}$ & $1.81 \pm 0.11$ & $\begin{array}{c}77.3 \pm 4.8 \\
\%\end{array}$ \\
\hline $4 \mathrm{oC}$ for $48 \mathrm{~h}$ & $1.62 \pm 0.06$ & $\begin{array}{c}69.0 \pm 2.3 \\
\%\end{array}$ \\
\hline $25 \mathrm{oC}$ for $48 \mathrm{~h}$ & $1.66 \pm 0.01$ & $\begin{array}{c}71.0 \pm 0.5 \\
\%\end{array}$ \\
\hline
\end{tabular}

Assessment of spontaneous differentiation of hESC colonies after exposure to reduced temperature

After exposure to low temperature, the hESC were incubated at $37^{\circ} \mathrm{C}$ for 1 to $2 \mathrm{~h}$ in the presence of fresh culture media, prior to being subjected to serial passage and replated on a fresh MEF feeder layer. After 4 days of culture following serial passage (P52 to P55), the degree of spontaneous differentiation of the hESC colonies was assessed by morphological observations under bright-field and phase-contrast microscopy, as well as by immunocytochemical staining for the pluripotency markers SSEA-3 and TRA-1- 
81 [4]. Briefly, the cells were fixed in $3.7 \%$ formaldehyde solution for $30 \mathrm{~min}$ at $37{ }^{\circ} \mathrm{C}$, washed with PBS $(3 \times)$, and exposed to blocking buffer (1\% BSA in PBS) for a further $30 \mathrm{~min}$ at $37{ }^{\circ} \mathrm{C}$, so as to minimize nonspecific adsorption of the antibodies. After another wash in PBS (3×), the cells were incubated with a mixture of diluted primary antibodies against SSEA-3 (mouse IgM, $10 \mu \mathrm{g} / \mathrm{ml}$ ) and TRA-1-81 (mouse IgG, 10 $\mu \mathrm{g} / \mathrm{ml}$ ) for $1 \mathrm{~h}$ at room temperature. The antibody mixture solution was then removed and the cells subsequently washed in PBS $(3 \times)$ again, before incubation for a further $1 \mathrm{~h}$ at room temperature with a mixture of secondary antibodies: FITC-conjugated rabbit anti-mouse IgM

$(10 \mu \mathrm{g} / \mathrm{ml})$ and rhodamine-

conjugated rat anti-mouse $\mathrm{IgG}$ $(10 \mu \mathrm{g} / \mathrm{ml})$. All primary and secondary antibodies were purchased from Chemicon Inc. (Temecula, CA, USA). Positive expression of SSEA-3 was indicated by green fluorescence under a wavelength of $490 \mathrm{~nm}$ (FITC), while positive expression of TRA-1-81 was indicated by red fluorescence under a wavelength of 570 nm (Rhodamine).

The hESC colonies were assigned into 3 grades [9] according to their degree of spontaneous differentiation (Figure 1): (1) Grade A that was completely or mostly undifferentiated, which is characterized by uniform cell morphology throughout the entire colony with distinct sharp boundaries together with strong expression of both SSEA-3 and TRA-1-81; (2) Grade B that was partially differentiated, with some areas of nonuniform cell morphology and non-distinct boundaries but with still relatively strong expression of SSEA-3 and TRA-1-81; and 3) Grade C that was mostly differentiated, which is characterized by non-uniform cell morphology throughout the colony with ill-de-

\section{Phase contrast}

\section{SSEA-3}

fined boundaries, and with weak expression of SSEA3 and TRA-1-81. A total of 200 colonies were examined for each experimental group, as well as for the control. Statistical comparison of data was performed by the Chi-squared test. A value of $\mathrm{P}<0.05$ was taken to be significantly different.

Figure 1. hESC colonies were graded according to their degree of spontaneous differentiation: Grade A which was completely or mostly undifferentiated, Grade B which was partially differentiated, and Grade C which was mostly differentiated.

\section{Assessment of chromosomal normality of hESC after} Grade B Grade C
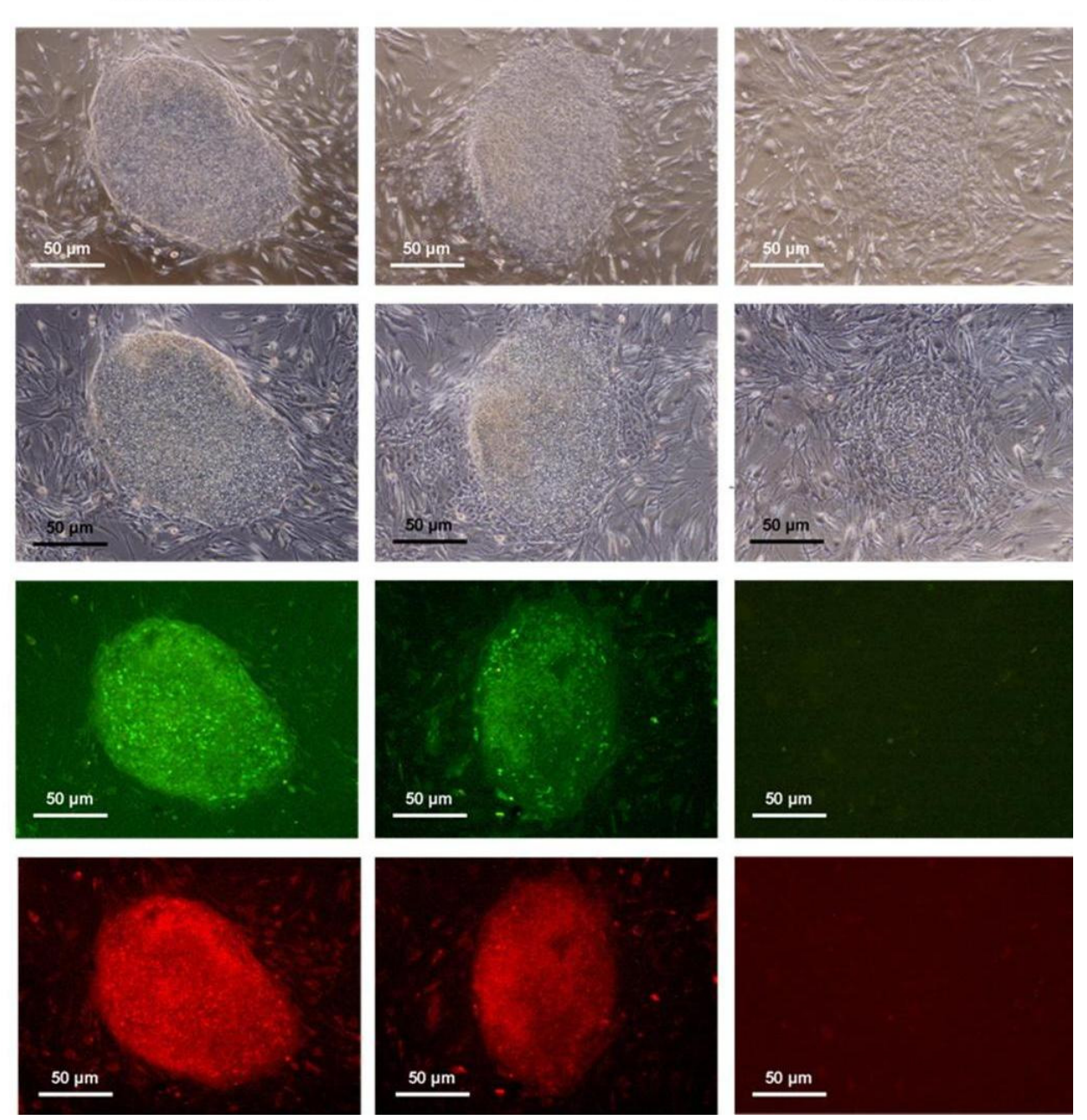

exposure to low temperature

The chromosomes of hESC upon exposure to low temperature $\left(25^{\circ} \mathrm{C}\right.$ and $4^{\circ} \mathrm{C}$ for $24 \mathrm{~h}$ and $\left.48 \mathrm{~h}\right)$ was analyzed by fluorescence in situ hybridization (FISH) of metaphase spreads (Figure 2A to E) with telomere and centromere-specific peptide nucleic acid (PNA) probes [5]. Following low temperature exposure, the hESC were cultured for a further $24 \mathrm{~h}$ at $37^{\circ} \mathrm{C}$, so as to enable some of the cells to undergo mitosis. Mitotic hESC were then arrested at metaphase by colcemid treatment $(0.1 \mu \mathrm{g} / \mathrm{ml})$ for $16-18 \mathrm{~h}$. Subsequently, the cells were subjected to hypotonic treatment with 0.075 
$\mathrm{M} \mathrm{KCl}$ for $2 \mathrm{~min}$ at $37^{\circ} \mathrm{C}$ and fixed on slides with Carnoy's fixative (3:1 methanol:acetic acid).

FISH was subsequently carried out with telomere-specific PNA probe $(5 \mu \mathrm{g} / \mathrm{ml})$ labeled with Cy3 (red fluorescence under an excitation wavelength of $559 \mathrm{~nm}$ ), and centromere-specific PNA probe (30 $\mu \mathrm{g} / \mathrm{ml}$ ) labeled with FITC (green fluorescence under an excitation wavelength of $495 \mathrm{~nm}$ ). Both PNA probes were obtained from Applied Biosystems Inc. (Foster City, CA, USA). Additionally, the chromosomes were also counterstained with $0.0375 \mu \mathrm{g} / \mathrm{ml}$ of 4, 6-diamidino-2-phenylindole (DAPI, light blue fluorescence under an excitation wavelength of 345 $\mathrm{nm})$. For each experimental group, fifty metaphase spreads (Figure $2 \mathrm{~A}$ to $\mathrm{E}$ ) were captured under a Zeiss Axioplan-2 fluorescence microscope (Carl Zeiss $\mathrm{GmbH}$, Oberkochen, Germany) equipped with a cooled charged device (CCD) camera (Sensicam).

These were then analyzed for chromosomal ploidy as well as for the presence of breaks and
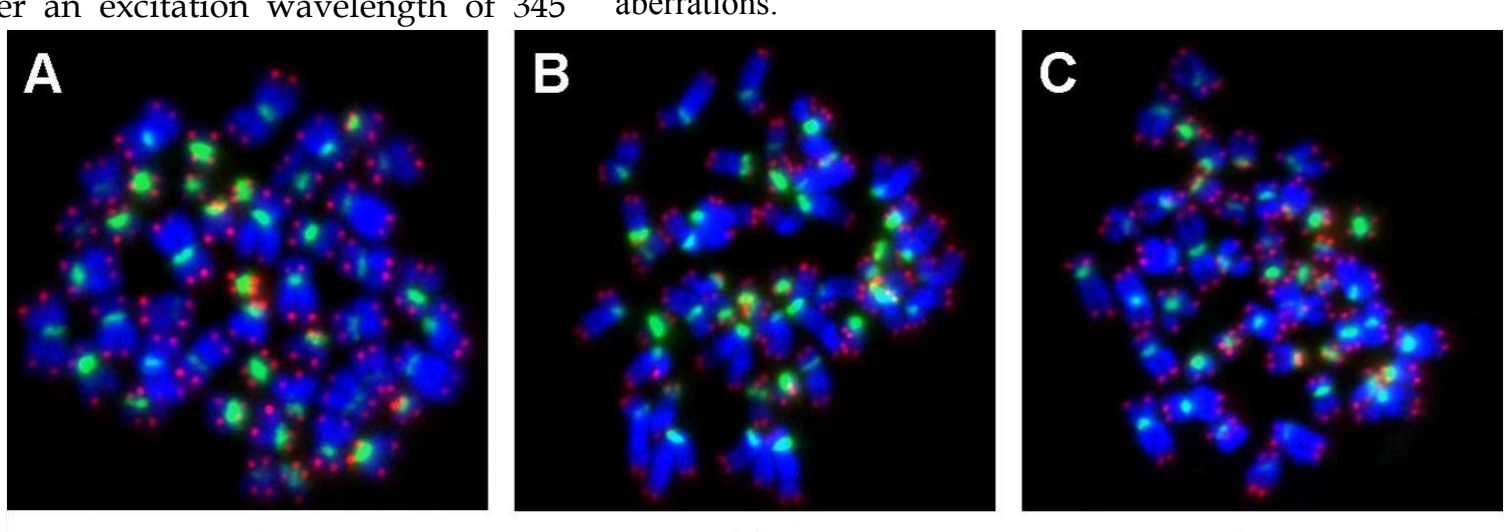

Fire 2. PNA-FISH on metaphase spreads obtained from hESC exposed to (A) physiological control maintained at $37^{\circ} \mathrm{C}$, (B) $4^{\circ} \mathrm{C}$ for $24 \mathrm{~h}$, (C) $25^{\circ} \mathrm{C}$ for $24 \mathrm{~h}$, (D) $4^{\circ} \mathrm{C}$ for $48 \mathrm{~h},(\mathrm{E})$ $25^{\circ} \mathrm{C}$ for $48 \mathrm{~h}$, The chromosomes were counterstained with DAPI (blue fluorescence). The telomere-specific PNA probe displayed red fluorescence, while the centromerespecific PNA probe displayed green fluorescence. In all experimental groups analyzed, there were no chromosomal aberrations.

the standard, partial-genome FISH labeling [12]. Experimental details of $\mathrm{mFISH}$ are described elsewhere [13, 14]. A total of 50 metaphase spreads for each experimental group were examined.

each experimental group were examined.
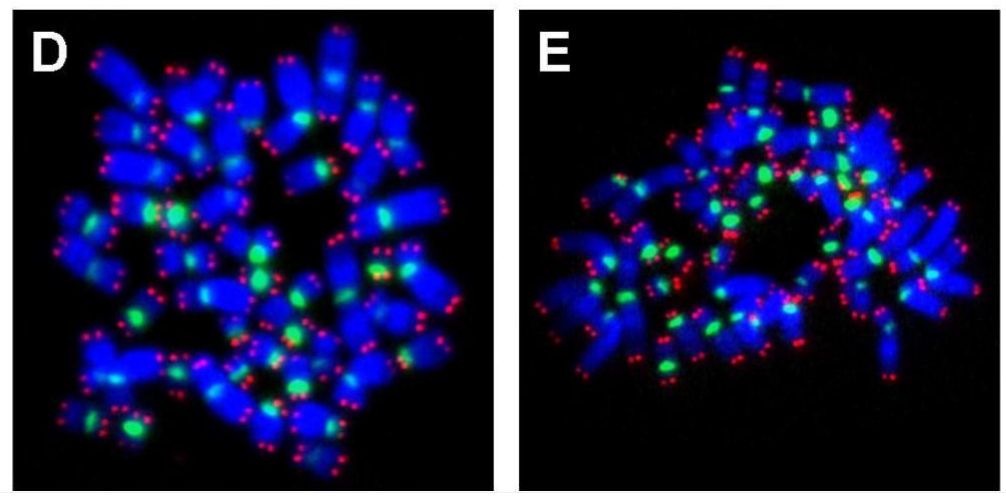

translocations

within individual chromosomes, utilizing the ISIS imaging software (Metasystems $\mathrm{GmbH}$, Altussheim, Germany).

Additionally, the mFISH assay [10] was used to screen for the presence of chromosomal translocations. Chromosome paints were obtained from MetaSystems $\mathrm{GmbH}$ (Altlussheim, Germany). Microscopic analysis was performed using a Zeiss Axioplan-2 fluorescence microscope (Carl Zeiss GmbH, Oberkochen, Germany) with an HBO-103 mercury lamp and filter sets for FITC, Cy3.5, Texas Red, Cy5, Aqua, and DAPI. Images were captured, processed, and analyzed using ISIS $\mathrm{mBAND} / \mathrm{mFISH}$ imaging software (MetaSystems $\mathrm{GmbH}$, Altlussheim, Germany). In the mFISH technique, each chromosome (1-22 and $\mathrm{X}$ and $\mathrm{Y})$ is painted a different color, using combinatorial labeling, so that any interchromosomal translocations are observed as color junctions on individual chromosomes. Painting every chromosome a different color significantly improves the precision and accuracy of translocation scoring [11], compared with

\section{Results}

\section{Survival rate of hESC after exposure to low temperature}

As seen in Table 1, the MTT assay yielded lower raw absorbance values upon incubation at $25^{\circ} \mathrm{C}$ and $4^{\circ} \mathrm{C}$ for extended durations (24h and $48 \mathrm{~h}$ ) as compared to the unexposed control; which in turn correlated to loss of cell viability upon exposure to low temperature. It was observed that some cells detached after exposure to low temperature. Virtually all of the detached cells were determined to be non-viable with tryphan blue staining (data not shown). All of the detached cells were washed off prior to the MTT assay. From the raw absorbance values, the survival rate was computed by a simple formula based on reference to the initial absorbance value obtained for the unexposed control (Table 1). The survival rates of hESC after exposure to $25^{\circ} \mathrm{C}$ and $4{ }^{\circ} \mathrm{C}$ for $24 \mathrm{~h}$ was 77.3 $\pm 4.8 \%$ and $64.4 \pm 4.4 \%$ respectively (significantly different, $\mathrm{P}<0.05)$. The corresponding survival rates 
after $48 \mathrm{~h}$ exposure to $25^{\circ} \mathrm{C}$ and $4^{\circ} \mathrm{C}$ was $71.0 \pm 0.5 \%$ and $69.0 \pm 2.3 \%$ respectively (not significantly different, $\mathrm{P}>0.05$ ). Hence, the results demonstrated that the majority of hESC survived exposure to low temperature for extended durations.

\section{Spontaneous differentiation of hESC after exposure to low temperature}

Following serial passage after exposure to low temperature, the proportion of Grade A, B and C colonies were $94.5 \%, 3.0 \%$ and $2.5 \%$ respectively for $24 \mathrm{~h}$ exposure to $4{ }^{\circ} \mathrm{C}(n=200)$; and $97.5 \%, 1.0 \%$ and $1.5 \%$ respectively for $24 \mathrm{~h}$ exposure to $25^{\circ} \mathrm{C}(n=200)$. The proportion of Grade A, B and C colonies were $95.5 \%, 2.5 \%$ and $2.0 \%$ respectively for $48 \mathrm{~h}$ exposure to $4^{\circ} \mathrm{C}(n=200)$; and $95.0 \%, 3.5 \%$ and $1.5 \%$ respectively for $48 \mathrm{~h}$ exposure to $25^{\circ} \mathrm{C} \quad(n=200)$. These were not significantly different $(\mathrm{P}>0.05)$ from the corresponding values of $97.0 \%, 2.5 \%$ and $0.5 \%$ obtained for the unexposed control maintained at $37^{\circ} \mathrm{C}(n=200)$. Some of the newly-passaged low-temperature exposed hESC were not fixed for immunostaining, but were instead kept continuously in culture through a number of serial passages. Their appearance was virtually indistinguishable from non-temperature exposed hESC (data not shown).

\section{Chromosomal Analysis of hESC after exposure to low temperature}

Metaphase spreads of hESC following lowtemperature exposure were subjected to FISH with telomere and centromere-specific PNA probes (Figure $2 \mathrm{~A}$ to E). Fifty FISH-metaphase spreads were examined for each experimental group (Figure 2A to E), the results demonstrated that hESC had maintained normal karyotype $(2 \mathrm{n}=46$ chromosomes) in all low temperature exposed groups $\left(4^{\circ} \mathrm{C}\right.$ and $25^{\circ} \mathrm{C}$ exposure for $24 \mathrm{~h}$ and $48 \mathrm{~h}$ ). No visible chromosome aberrations (such as fusions and breaks) were detected in the exposed samples. Further analysis of metaphase spreads from different experimental samples using mFISH (24-colour FISH) revealed absence of chromosome translocations demonstrating that low temperature exposure does not induce chromosome alterations.

\section{Discussion}

It is a well-established fact that early-stage mammalian embryos and oocytes rapidly lose their viability even upon relatively short durations of exposure to low temperature [15, 16]. Although later stage pre-implantation embryos of mice (8-cell and older) can be shipped overnight at room temperature with no apparent ill effects, the same cannot be said of human embryos, which are much less robust and hardy compared to mouse embryos. Hence laboratories involved in handling human embryos in clinical assisted reproduction often have special apparatus and equipment to minimize their exposure to low temperature i.e. heated microscope stage, test tube warmer, temperature-controlled room [15, 16]. Additionally, laboratory personnel are also specially trained in procedures and protocols designed to minimize low temperature exposure. This would include quick handling outside the incubator, as well as the use of pre-warmed and pre-equilibrated culture media $[15,16]$. Indeed, minimizing low temperature exposure of human embryos and oocytes is a critical factor in determining the success of clinical assisted reproduction $[15,16]$.

Figure 3. m-FISH on metaphase spreads obtained from hESC exposed to (A1) physiological control maintained at $37^{\circ} \mathrm{C}$, (B1) $4^{\circ} \mathrm{C}$ for $24 \mathrm{~h},(\mathrm{C} 1) 25^{\circ} \mathrm{C}$ for $24 \mathrm{~h}$, (D1) $4^{\circ} \mathrm{C}$ for $48 \mathrm{~h},(\mathrm{E} 1) 25^{\circ} \mathrm{C}$ for $48 \mathrm{~h}$. The corresponding karyotypes (A2 to E2) were analyzed by the ISIS imaging software (Metasystems GmbH, Altussheim, Germany). In all experimental groups analyzed, no chromosomal translocations were detected.
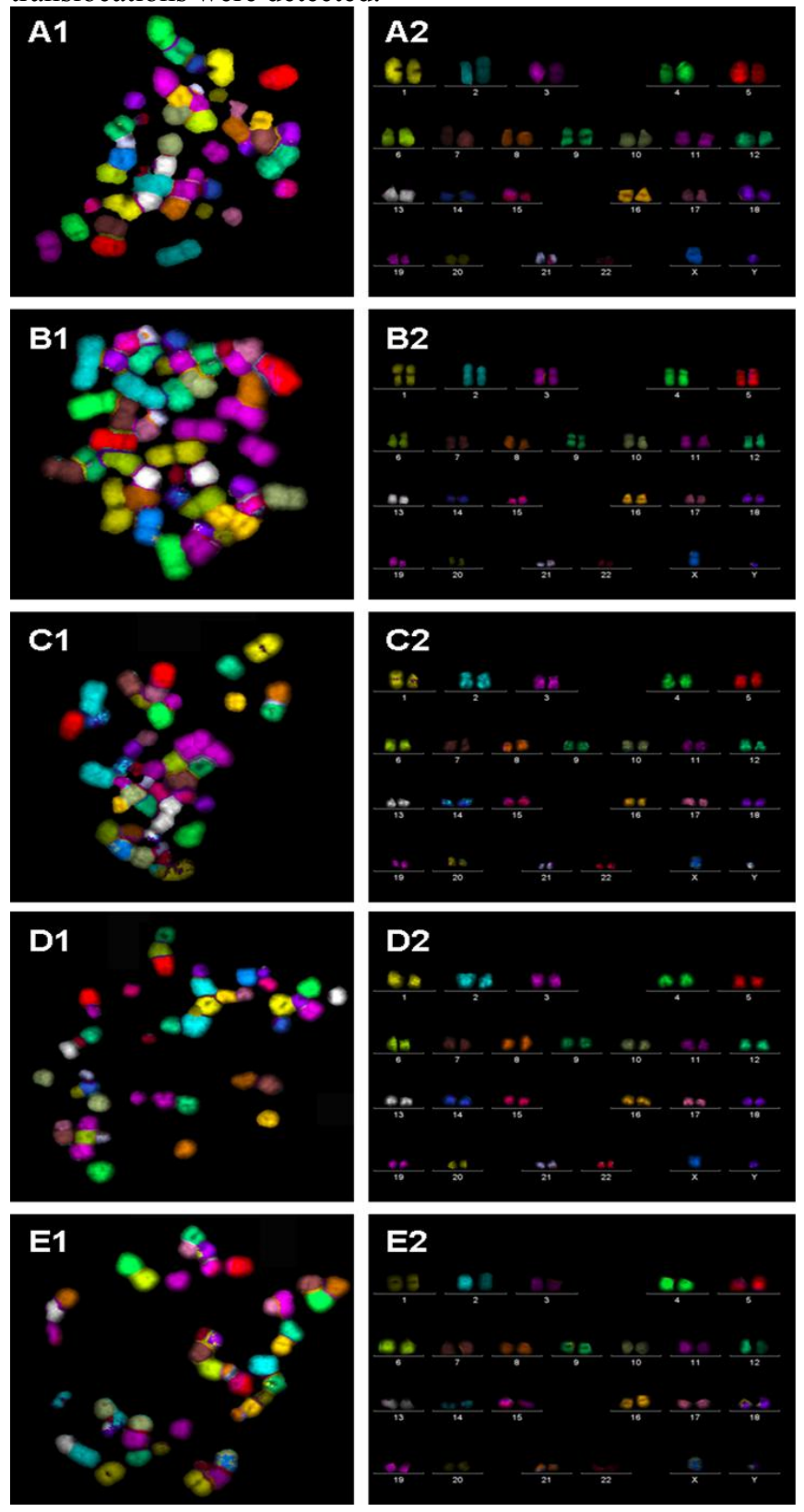

Initially, when hESC were first isolated from blastocyst stage embryos, it was somewhat assumed 
that these cells were also highly sensitive to low temperature exposure, just like the embryos from which they originated. Hence, the first few reported studies $[7,8]$ on the establishment of new hESC lines emphasized the use of temperature-heated stage and pre-warmed and pre-equilibrated culture media.

Nevertheless, the results of this study would prove otherwise. hESC of the H9 line isolated by Thomson and colleagues [7] was demonstrated to possess relatively high tolerance to prolonged durations of low temperature exposure. Even after 24 and $48 \mathrm{~h}$ exposure to $25^{\circ} \mathrm{C}$ and $4^{\circ} \mathrm{C}$, at least $65 \%$ to $70 \%$ of the cells survived (Table 1), as assessed by the MTT assay. In all low temperature-exposed experimental groups, there was no significant increase in the spontaneous differentiation rate of hESC compared to the physiological control maintained at $37^{\circ} \mathrm{C}$. In fact $>$ $95 \%$ of hESC colonies remained undifferentiated in all low temperature-exposed groups. Additionally, low temperature exposure also did not result in any chromosomal aberrations, as confirmed by PNA-FISH (Figure 2) and m-FISH (Figure 3) of metaphase spreads.

Hence, the results of this study could have useful implications for the salvage of hESC culture during infrequent occurrences of incubator break-down and power failure, either in small-scale culture for research or large-scale culture within bioreactors.

\section{Conflicts of interest}

The authors have declared that no conflict of interest exists.

\section{References}

1. Becker EW. The roles of ATP in the dynamics of the actin filaments of the cytoskeleton. Biol Chem. 2006;387(4):401-6.

2. Lopez LA, Bertini F. The in vivo effect of low body temperatures on the degree of polymerization of tubulin in brain and testes: a comparison among some species of vertebrates. Comp Biochem Physiol A. 1986;83(2):317-20.

3. Mosmann T. Rapid colorimetric assay for cellular growth and survival: application to proliferation and cytotoxicity assays. J Immunol Methods 1983; 65: 55-63.

4. Heng BC, Liu H, Rufaihah AJ, Cao T. Human embryonic stem cell (HESC) colonies display a higher degree of spontaneous differentiation when passaged at lower densities. In Vitro Cell Dev Biol Anim. 2006;42(3-4):54-7.

5. Hande MP, Samper E, Lansdorp P, Blasco MA. Telomere length dynamics and chromosomal instability in cells derived from telomerase null mice. J Cell Biol 1999;144: 589-601.

6. Ready T. NIH posts online ES-cell registry. Nat Med. 2001;7(12):1262.

7. Thomson JA, Itskovitz-Eldor J, Shapiro SS, Waknitz MA, Swiergiel JJ, Marshall VS, Jones JM. Embryonic stem cell lines derived from human blastocysts. Science. 1998;282(5391):1145-7.

8. Reubinoff BE, Pera MF, Fong CY, Trounson A, Bongso A. Embryonic stem cell lines from human blastocysts: somatic differentiation in vitro. Nat Biotechnol. 2000;18(4):399-404.

9. Richards M, Fong CY, Tan S, Chan WK, Bongso A. An efficient and safe xeno-free cryopreservation method for the storage of human embryonic stem cells. Stem Cells. 2004;22(5):779-89.

10. Speicher MR, Ballard SG, Ward DC. Karyotyping human chromosomes by combinatorial multi-fluor FISH. Nat Genet $1996 ; 12: 368-375$.
11. Greulich KM, Kreja L, Heinze B, Rhein AP, Weier HUG, Bruckner M, Fuchs P, Molls M. Rapid detection of radiationinduced chromosomal aberrations in lymphocytes and hematopoietic progenitor cells by mFISH. Mutat Res 2000; 452:73-81.

12. Tucker JD. Fish cytogenetics and the future of radiation biodosimetry. Radiat Prot Dosim 2001; 97:55-60.

13. Hande MP, Azizova TV, Geard CR, Burak LE, Mitchell CR, Khokhryakov VF, Vasilenko FK, Brenner DJ. Past exposure to densely ionizing radiation leaves a unique permanent signature in the genome. American Journal of Human Genetics 2003; 72 (5): 1162-1170.

14. Hande MP, Azizova TV, Burak LE, Khokhryakov VF, Geard CR, Brenner DJ. Complex chromosome aberrations persist in individuals many years after occupational exposure to densely ionizing radiation: An mFISH study. Genes, Chromosomes and Cancer 2005; 44 (1): 1-9.

15. Trounson A and Gardner DK. Handbook of in vitro fertilization. Boca Raton : CRC press, 1999.

16. Gardner DK. Textbook of assisted reproductive techniques: laboratory and clinical perspectives. London, New York: Taylor \& Francis Ltd. 2004. 